\title{
Resistance Patterns of Gram-Negative Bacteria Recovered from Clinical Specimens of Intensive Care Patients
}

\author{
Farooq Ahmed Wani ${ }^{1, *}$, Altaf Bandy ${ }^{2}\left(\mathbb{0}\right.$, , Mohammed Jayed S. Alenzi ${ }^{3}$, Abdulaziz Ibrahim Alzarea ${ }^{4}(\mathbb{D}$, \\ Abdullah S. Alanazi ${ }^{4,5}$, Mohammed Ubaidullah Sayeed ${ }^{1}$, Ashokkumar Thirunavukkarasu ${ }^{2}$, Bilal Tantry ${ }^{6}$ \\ and Mushtaq Dar ${ }^{7}$
}

1 Department of Pathology, College of Medicine, Jouf University, Sakaka 72388, Saudi Arabia; usmohammed@ju.edu.sa

2 Department of Community Medicine, College of Medicine, Jouf University, Sakaka 72388, Saudi Arabia; drbanday@gmail.com (A.B.); ashokkumar@ju.edu.sa (A.T.)

3 Department of Surgery, College of Medicine, Jouf University, Sakaka 72388, Saudi Arabia; mja@ju.edu.sa

4 Department of Clinical Pharmacy, College of Pharmacy, Jouf University, Sakaka 72388, Saudi Arabia; aizarea@ju.edu.sa (A.I.A.); Asdalananzi@ju.edu.sa (A.S.A.)

5 Health Sciences Research Unit, Jouf University, Sakaka 72388, Saudi Arabia

6 Department of Microbiology, Government Medical College, Kashmir University, Srinagar 190006, India; bilaltantry@gmail.com

7 Ministry of Interiors, Jeddah 21577, Saudi Arabia; mushtaq164364@gmail.com

* Correspondence: fawani@ju.edu.sa; Tel.: +966-59-375-0779

check for updates

Citation: Wani, F.A.; Bandy, A.; Alenzi, M.J.S.; Alzarea, A.I.; Alanazi, A.S.; Sayeed, M.U.;

Thirunavukkarasu, A.; Tantry, B.; Dar,

M. Resistance Patterns of

Gram-Negative Bacteria Recovered from Clinical Specimens of Intensive Care Patients. Microorganisms 2021, 9 , 2246. https://doi.org/10.3390/ microorganisms 9112246

Academic Editor: Thierry Naas

Received: 2 October 2021

Accepted: 25 October 2021

Published: 28 October 2021

Publisher's Note: MDPI stays neutral with regard to jurisdictional claims in published maps and institutional affiliations.

Copyright: (c) 2021 by the authors. Licensee MDPI, Basel, Switzerland. This article is an open access article distributed under the terms and conditions of the Creative Commons Attribution (CC BY) license (https:// creativecommons.org/licenses/by/ $4.0 /)$.

\begin{abstract}
Intensive care units are complex environments favoring high resistance in microorganisms. This study evaluated the resistance and the distribution dynamics of resistant Gram-negative bacteria (GNB) in patients admitted to intensive care units. This retrospective, record-based, cross-sectional study analyzed all of the antibiograms of patients admitted to the ICUs. The BD Phoenix system (BD Diagnostics, Sparks, MD, USA) was used for bacterial identification and antimicrobial testing. Clinical and Laboratory Standard Institute recommendations were used for antimicrobial testing. Frequencies and percentages of multidrug and pan-drug resistance were calculated. A total of 570 bacterial growths were observed, out of which 437 (76.7\%) were of GNB. K. pneumoniae (21.0\%), P. aeruginosa (11.8\%), and Staphylococcus aureus (13.2\%) were the most frequent disease-causing bacteria in intensive care patients. Resistance rates of $73.2 \%$ and $70.1 \%$ were observed for third- and fourth-generation cephalosporins, respectively, while $48.2 \%$ carbapenem and $>65 \%$ fluoroquinolones resistance rates were observed. Amikacin was the most effective antibiotic, with a sensitivity rate of $69.5 \%$. A total of $372(85.1 \%)$ of GNB were multidrug resistant. The majority of infections in intensive care patients are caused by multidrug-resistant (MDR) Gram-negative bacteria. Female gender and advancing age are factors favoring MDR. Enhanced surveillance and strengthening of the antimicrobial stewardship program are warranted.
\end{abstract}

Keywords: intensive care units; Gram-negative bacteria; antimicrobial resistance; multidrug resistance; carbapenems

\section{Introduction}

Antimicrobial resistance is being increasingly recognized throughout the world, and is offsetting the success story of antibiotics. The world is encountering a grave threat of resistant bacterial infections, which have emerged as a significant public health problem. Microorganisms are developing new resistance mechanisms that increase their capacity to spread globally and cause prolonged illness, disability, and death. In the absence of efficacious antimicrobials, medical procedures are becoming increasingly risky, and result in more extended hospital stays, often requiring intensive care [1]. Although emanation of antimicrobial resistance is considered to be a natural phenomenon, it may be driven by the use of antimicrobial agents in healthcare settings, agriculture, and the environment. 
The drivers of increased antimicrobial resistance may include lack of optimal usage of antimicrobials, environmental contamination with antimicrobials, poor infection control measures, lack of sanitation and restricted access to clean water, increased international travel, and migration [2].

The World Health Organization (WHO) has published a list of antibiotic-resistant "priority pathogens" that includes 12 families of bacteria that constitute the greatest threat to human health. The list is divided into critical-, high-, and medium-priority pathogens. The critical group includes Gram-negative multidrug-resistant bacteria (Enterobacterales such as K. pneumoniae, E. coli, S. marcescens, and P. mirabilis; A. baumannii, and P. aeruginosa). These Gram-negative bacteria (GNB) have acquired resistance to the best accessible antibiotics, including carbapenems and cephalosporins [3]. These multidrug-resistant (MDR) organisms have been reported throughout the globe, posing great therapeutic challenges and resulting in increased morbidity and mortality [4].

Health care-associated infections (HCAIs) are being reported increasingly in developed and developing countries. The WHO reports a pooled prevalence of HCAIs of $7.6 \%$ in mixed patient populations in high-income countries (1995-2010), ranging from as low as $3.6 \%$ in Germany to as high as $12 \%$ in New Zealand. The same WHO report observed pooled prevalence of HCAIs of $15.5 \%$ in mixed patient populations in low- and middleincome countries (1995-2010), ranging from 5.4\% in Mongolia to 19.1\% in Albania [5]. The EPIC II study noted that $51 \%$ of the patients admitted to the ICUs were infected, thereby indicating infection as a significant reason for increased morbidity and mortality in the ICUs [6] Patients admitted to the ICUs are particularly prone to developing infections because of numerous risk factors, including the presence of comorbid conditions, central venous catheterization, mechanical ventilation, urinary catheterization, usage of steroid and antibiotics, and lengthier ICU stays [7]. Infections acquired in ICUs are an independent risk factor for increased hospital mortality [8].

Although many studies have been carried out in Saudi Arabia [9-12] regarding GNB in ICU settings, studies from the northern region are scarce. The present study was planned keeping in view the necessity of having regional data on antimicrobial resistance that can be used for planning and implementing the antimicrobial stewardship programs so as to improve the clinical outcomes of the patients admitted to the intensive care units. We evaluated the resistance patterns-especially the MDR patterns-and the distribution dynamics of the resistant Gram-negative bacteria in patients admitted to intensive care units.

\section{Materials and Methods}

\subsection{Study Design}

The study was conducted in a referral hospital situated in the city of Sakaka in the Al-Jouf region for a period of one year, and was completed by December 2020. This region lies in the north of Saudi Arabia. This study followed a single-center, record-based, cross-sectional design. The research project was approved by the Jouf University's Local Committee on Bio-Ethics via research protocol no. 03/04/41 dated 6 January 2020. As our study involved the analysis of antibiograms from the microbiology unit of the study hospital, there was no direct contact with the patients; hence, no consent was required. However, as a standard operating procedure practiced in this hospital, patients' and/or relatives' consent is taken before carrying out any procedure on patients admitted to ICUs, and the same is recorded in the files.

\subsection{Bacterial Identification and Antimicrobial Susceptibility Testing}

The BD Phoenix system (BD Diagnostics, Sparks, MD, USA) was used for bacterial identification and testing. Clinical and Laboratory Standard Institute guidelines were used for antimicrobial testing and its interpretation [13]. Distribution data of clinical specimens, along with patient demographics, were also retrieved. The resistance patterns exhibited by the bacteria were based on an earlier classification by Magiorakos et al. [14]. 
The antibiotic panel consisted of amikacin (AMK), gentamicin (GEN), ertapenem (ETP), imipenem (IPM), meropenem (MEM), cephalothin (CEF), cefuroxime (axetil or sodium) (CXM), cefoxitin (FOX), ceftazidime (CAZ), ceftriaxone (CRO), cefepime (FEP), aztreonam (ATM), ampicillin (AMP), amoxicillin/clavulanic acid (AMC), piperacillin/tazobactam (TZP), colistin (CST), trimethoprim/sulfamethoxazole (SXT), nitrofurantoin (NIT), ciprofloxacin (CIP), levofloxacin (LVX), and tigecycline (TGC).

\subsection{Statistical Analysis}

Data on the antimicrobial test results were coded before entry. The correctness of data entry was ensured independently by researchers. Intermediate resistance exhibited by the microorganisms was considered resistant for this study. Data were analyzed using Statistical Package for the Social Sciences (SPSS) version 22.0 for Windows (IBM SPSS Statistics, IBM Corporation, Armonk, NY, USA). Frequencies and percentages of MDR, extensive-drug resistant (XDR), Pan-drug resistant (PDR), and their distribution in clinical samples and different age groups were calculated.

\section{Results}

Of the 570 bacterial growths, 437 (76.7\%) were Gram-negative, and 133 (27.3\%) were Gram-positive isolations. A total of $313(55.0 \%)$ of these infections occurred in males, and $199(35.0 \%)$ in patients above 75 years of age. K. pneumoniae (21.0), P. aeruginosa (11.8\%), and Staphylococcus aureus (13.2\%) were the most common bacteria causing infections in intensive care patients. Bacteria were frequently isolated from blood $(28.8 \%)$ and urine $(23.5 \%)$ specimens. Almost half of the infections $(250 ; 43.9 \%)$ occurred in the first quarter (January to March) of the study period (Table 1).

Table 1. Bacteriological diversity and distribution of ICU pathogens $(n=570)$.

\begin{tabular}{|c|c|c|c|}
\hline \multicolumn{2}{|c|}{ Category } & \multirow{2}{*}{$\frac{\text { Number }(n)}{120}$} & \multirow{2}{*}{$\begin{array}{c}\text { Percentage (\%) } \\
21.0\end{array}$} \\
\hline \multirow{9}{*}{ Gram-negative bacteria [437 (76.7\%)] } & K. pneumoniae & & \\
\hline & P. aeruginosa & 67 & 11.8 \\
\hline & P. mirabilis & 66 & 11.6 \\
\hline & E. coli & 63 & 11.0 \\
\hline & A. baumannii & 39 & 6.8 \\
\hline & E. aerogenes & 16 & 2.8 \\
\hline & Providencia stuartii & 15 & 2.6 \\
\hline & S. marcescens & 15 & 2.6 \\
\hline & Others & 36 & 6.3 \\
\hline \multirow{7}{*}{ Gram-positive bacteria [133 (23.3\%)] } & Staphylococcus aureus & 75 & 13.2 \\
\hline & Enterococcus faecalis & 12 & 2.1 \\
\hline & Streptococcus spp. & 19 & 3.3 \\
\hline & Staphylococcus capitis & 5 & 0.9 \\
\hline & Staphylococcus haemolyticus & 4 & 0.7 \\
\hline & Staphylococcus epidermidis & 3 & 0.5 \\
\hline & Others & 15 & 2.6 \\
\hline \multirow{2}{*}{ Gender } & Males & 313 & 55.0 \\
\hline & Females & 257 & 45.0 \\
\hline \multirow{4}{*}{ Quarter } & Quarter 1 & 250 & 43.9 \\
\hline & Quarter 2 & 136 & 23.9 \\
\hline & Quarter 3 & 76 & 13.3 \\
\hline & Quarter 4 & 108 & 19.0 \\
\hline \multirow{6}{*}{ Age (in years) } & $>75$ & 199 & 35.0 \\
\hline & $61-75$ & 118 & 20.7 \\
\hline & $46-60$ & 92 & 16.1 \\
\hline & $31-45$ & 52 & 9.1 \\
\hline & $16-30$ & 69 & 12.1 \\
\hline & $\leq 15$ & 40 & 7.0 \\
\hline
\end{tabular}


Table 1. Cont.

\begin{tabular}{cccc}
\hline & Category & Number $(n)$ & Percentage (\%) \\
\hline & Blood & 164 & 28.8 \\
& Urine & 134 & 23.5 \\
Type of specimen & Wound swab & 94 & 16.5 \\
& Sputum & 75 & 13.2 \\
& Nasal swab & 54 & 9.5 \\
& Tracheal wash & 23 & 4.0 \\
& Conjunctival swab & 18 & 3.2 \\
& Others & 8 & 1.4 \\
\hline
\end{tabular}

Of the 437 Gram-negative infections, 221 (50.6\%) occurred in males, and 141 (32.3\%) in patients aged more than 75 years. Nearly half $(47.7 \%)$ of the bacterial isolations were recovered in the first quarter. Urine specimens $(131 ; 30.0 \%)$ dominated the frequency of Gram-negative bacterial growths, followed by blood specimens (112; 25.6\%). The majority of the infections were caused by K. pneumoniae (27.5\%) (Table 2 and Figure 1 ).

Table 2. Distribution of Gram-negative bacteria isolated from ICU clinical specimens $(n=437)$.

\begin{tabular}{|c|c|c|c|}
\hline \multicolumn{2}{|c|}{ Category } & \multirow{3}{*}{$\begin{array}{c}\text { Number }(\boldsymbol{n}) \\
221 \\
216\end{array}$} & \multirow{3}{*}{$\begin{array}{c}\text { Percentage (\%) } \\
50.6 \\
49.4 \\
\end{array}$} \\
\hline & Males & & \\
\hline Gender & Females & & \\
\hline \multirow{9}{*}{ Name of the Gram-negative Bacteria } & K. pneumoniae & 120 & 27.5 \\
\hline & P. aeruginosa & 67 & 15.3 \\
\hline & P. mirabilis & 66 & 15.1 \\
\hline & E. coli & 63 & 14.4 \\
\hline & A. baumannii & 39 & 8.9 \\
\hline & E. aerogenes & 16 & 3.7 \\
\hline & Providencia stuartii & 15 & 3.4 \\
\hline & S. marcescens & 15 & 3.4 \\
\hline & Others & 36 & 8.2 \\
\hline \multirow{4}{*}{ Quarter } & Quarter 1 & 207 & 47.4 \\
\hline & Quarter 2 & 108 & 24.7 \\
\hline & Quarter 3 & 48 & 11.0 \\
\hline & Quarter 4 & 74 & 16.9 \\
\hline \multirow{6}{*}{ Age (in years) } & $>75$ & 141 & 32.3 \\
\hline & $61-75$ & 95 & 21.7 \\
\hline & $46-60$ & 78 & 17.8 \\
\hline & $31-45$ & 38 & 8.7 \\
\hline & $16-30$ & 58 & 13.3 \\
\hline & $\leq 15$ & 27 & 6.2 \\
\hline \multirow{7}{*}{ Type of specimen } & Urine & 131 & 30.0 \\
\hline & Blood & 112 & 25.6 \\
\hline & Wound swab & 86 & 19.7 \\
\hline & Sputum & 65 & 14.9 \\
\hline & Tracheal wash & 20 & 4.6 \\
\hline & Conjunctival swab & 17 & 3.9 \\
\hline & Others & 6 & 1.4 \\
\hline
\end{tabular}

The highest antimicrobial resistance was observed against ampicillin (95\%) and cephalothin (93.1\%). An overall 73.2\% and 70.1\% resistance was observed for third- and fourth-generation cephalosporins. An overall carbapenem resistance rate of $48.2 \%$ was observed, with the lowest for meropenem (43\%). A resistance rate of $>65 \%$ was observed for fluoroquinolones. Amikacin was the most effective antibiotic, with a sensitivity rate of $69.5 \%$ (Figure 2). 


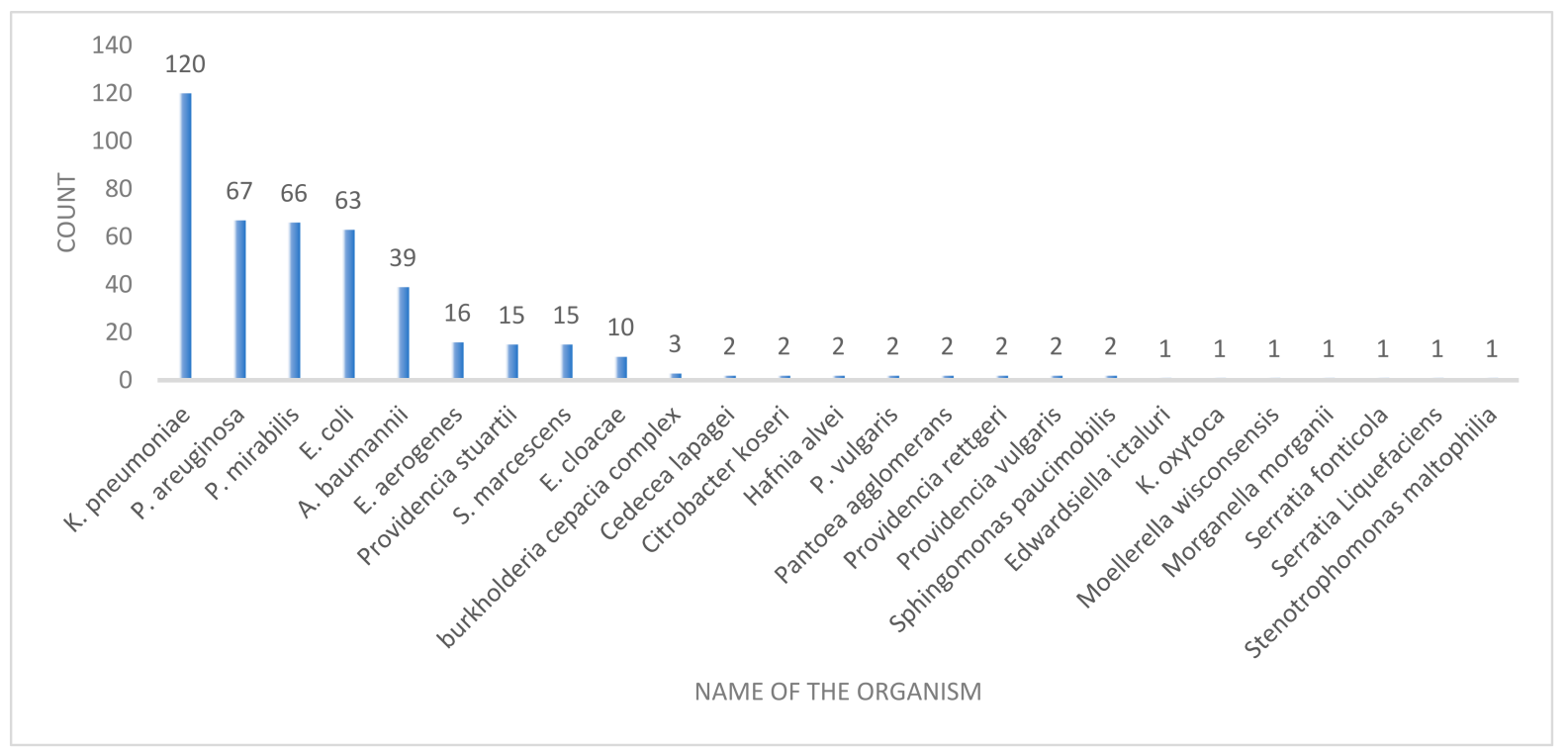

Figure 1. Gram-negative bacteria isolated from ICU patients.

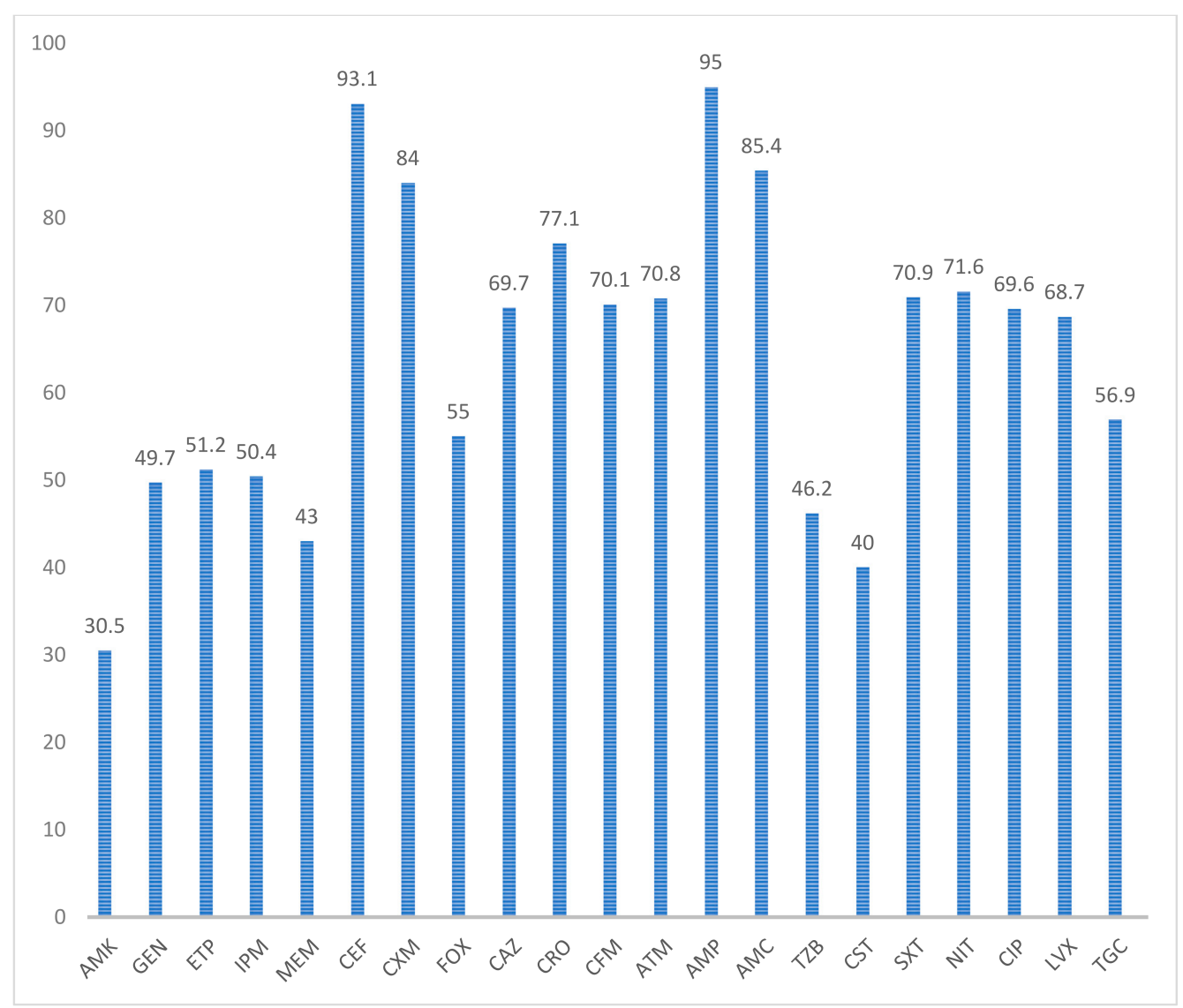

Figure 2. Antimicrobial resistance exhibited by Gram-negative organisms: amikacin (AMK), gentamicin (GEN), ertapenem (ETP), imipenem (IPM), meropenem (MEM), cephalothin (CEF), cefuroxime (axetil or sodium) (CXM), cefoxitin (FOX), ceftazidime (CAZ), ceftriaxone (CRO), cefepime (FEP), aztreonam (ATM), ampicillin (AMP), amoxicillin/clavulanic acid (AMC), piperacillin/tazobactam (TZP), colistin (CST), trimethoprim/sulfamethoxazole (SXT), nitrofurantoin (NIT), ciprofloxacin (CIP), levofloxacin (LVX), tigecycline (TGC).

Overall, $45(10.3 \%)$ were resistant to less than three antibiotic classes, while 372 $(85.1 \%)$ were multidrug resistant, which also included $125(28.6 \%)$ of the extensively 
drug-resistant and 20 (4.6\%) of the pan-drug-resistant isolates of the Gram-negative bacteria. All isolates of A. baumannii were multidrug-resistant strains, and all isolates of the Burkholderia cepacia complex were pan-drug resistant. Among the frequently isolated Gram-negative bacteria, 60 (95.2\%) of P. aeruginosa, 57 (86.4\%) of P. mirabilis, 100 (83.3\%) of a K. pneumoniae, and $50(79.4 \%)$ of E. coli were multidrug resistant (Table 3$)$.

Table 3. Numbers of Gram-negative isolates showing multidrug, extensive-, and pan-drug resistance.

\begin{tabular}{|c|c|c|c|c|}
\hline Microorganism & $<3$ abs* & $\mathrm{MDR}^{\wedge}$ & $\mathrm{XDR} \sim$ & PDR ** \\
\hline K. pneumoniae $(n=120)$ & 14 & 100 & 26 & 6 \\
\hline P. aeruginosa $(n=67)$ & 3 & 60 & 26 & 4 \\
\hline P. mirabilis $(n=66)$ & 8 & 57 & 6 & 1 \\
\hline E. $\operatorname{coli}(n=63)$ & 13 & 50 & 13 & 0 \\
\hline A. baumannii $(n=39)$ & 0 & 39 & 31 & 0 \\
\hline E. aerogenes $(n=16)$ & 1 & 13 & 11 & 2 \\
\hline S. marcescens $(n=15)$ & 1 & 12 & 0 & 2 \\
\hline E. cloacae $(n=10)$ & 1 & 9 & 3 & 0 \\
\hline Burkholderia cepacia complex $(n=3)$ & 0 & 0 & 0 & 3 \\
\hline Cedecea lapagei $(n=2)$ & 0 & 2 & 1 & 0 \\
\hline Citrobacter koseri $(n=2)$ & 0 & 2 & 0 & 0 \\
\hline Hafnia alvei $(n=2)$ & 0 & 0 & 0 & 2 \\
\hline P. vulgaris $(n=2)$ & 0 & 2 & 0 & 0 \\
\hline Pantoea agglomerans $(n=2)$ & 0 & 2 & 0 & 0 \\
\hline Providencia rettgeri $(n=2)$ & 0 & 2 & 1 & 0 \\
\hline Providencia stuartii $(n=2)$ & 2 & 13 & 4 & 0 \\
\hline Providencia vulgaris $(n=2)$ & 0 & 2 & 1 & 0 \\
\hline Stenotrophomonas maltophilia $(n=2)$ & 0 & 1 & 1 & 0 \\
\hline Edwardsiella ictaluri $(n=1)$ & 0 & 1 & 0 & 0 \\
\hline K. oxytoca $(n=1)$ & 0 & 1 & 0 & 0 \\
\hline Moellerella wisconsensis $(n=1)$ & 0 & 1 & 0 & 0 \\
\hline Morganella morganii $(n=1)$ & 0 & 1 & 0 & 0 \\
\hline Serratia fonticola $(n=1)$ & 0 & 1 & 1 & 0 \\
\hline Serratia Liquefaciens $(n=1)$ & 0 & 1 & 0 & 0 \\
\hline Sphingomonas paucimobilis $(n=1)$ & 2 & 0 & 0 & 0 \\
\hline Total (437) & $45(10.3 \%)$ & $372(85.1 \%)$ & $125(28.6 \%)$ & $20(4.6 \%)$ \\
\hline
\end{tabular}

* abs: antibiotics; ${ }^{\wedge}$ MDR: multidrug resistant; $~$ XDR: extensively drug resistant; and ${ }^{* *}$ PDR: pan-drug resistant.

As regards the multidrug-resistant strains, $88.9 \%$ were recovered from female patients and $81.45 \%$ from male patients admitted to intensive care units. MDR isolation rates of around $90 \%$ were observed for the blood, tracheal wash, and sputum samples. MDR isolates were also recovered at a higher frequency $(>75 \%)$ from all age groups (Table 4 ).

Table 4. Distribution of numbers of multidrug-, extensively drug-, and pan-drug-resistant isolates among different categories of patients.

\begin{tabular}{|c|c|c|c|c|}
\hline Characteristic & $<3$ abs * & $\mathrm{MDR}^{\wedge}$ & XDR & PDR ** \\
\hline \multicolumn{5}{|c|}{ Gender } \\
\hline Male $(n=221)$ & 29 & 180 & 56 & 12 \\
\hline Female $(n=216)$ & 16 & 192 & 69 & 8 \\
\hline \multicolumn{5}{|c|}{ Type of sample } \\
\hline Urine $(n=131)$ & 24 & 106 & 22 & 1 \\
\hline Blood $(n=112)$ & 8 & 101 & 42 & 3 \\
\hline Wound swab $(n=86)$ & 10 & 71 & 27 & 5 \\
\hline Sputum $(n=65)$ & 0 & 59 & 19 & 6 \\
\hline Tracheal wash $(n=20)$ & 1 & 18 & 8 & 1 \\
\hline Conjunctival swab $(n=17)$ & 2 & 12 & 3 & 3 \\
\hline Others $(n=6)$ & 0 & 5 & 4 & 1 \\
\hline
\end{tabular}


Table 4. Cont.

\begin{tabular}{|c|c|c|c|c|}
\hline Characteristic & $<3 \mathrm{abs}^{*}$ & $\mathrm{MDR}^{\wedge}$ & $\mathrm{XDR}^{\sim}$ & PDR ** \\
\hline \multicolumn{5}{|c|}{ Age (in years) } \\
\hline$>75(n=141)$ & 12 & 122 & 39 & 7 \\
\hline $61-75(n=95)$ & 9 & 83 & 27 & 3 \\
\hline $46-60(n=78)$ & 8 & 68 & 17 & 2 \\
\hline $31-45(n=38)$ & 4 & 31 & 14 & 3 \\
\hline $16-30(n=58)$ & 11 & 45 & 19 & 2 \\
\hline$\leq 15(n=27)$ & 1 & 23 & 9 & 3 \\
\hline
\end{tabular}

* abs: antibiotics; ^ MDR: multidrug resistant; XDR: extensively drug resistant; and ** PDR: pan-drug resistant.

\section{Discussion}

ICUs are sections of hospitals with a complex environment where multidrug-resistant organisms are maximal, posing significant difficulties in the treatment of patients [15]. The problem of MDR in ICU settings is diversified and multifold, as ICUs cater to critically ill patients afflicted with life-threatening conditions and infected with a wide variety of infectious agents [16]. The complexity of the ICU environment favors the acquisition and spread of nosocomial infections. ICU patients are increasingly subjected to invasive procedures such as central venous catheterization, arterial catheterization, intra-aortic balloon pump (IABP), tracheostomy, etc. They may have multiple indwelling devices such as urinary catheters, feeding tubes, etc., which serve as a continuous source of infectious agents and a potential point of entry for infectious organisms. Furthermore, the involvement of multiple healthcare professionals creates a desirable environment for the person-to-person transmission of infectious diseases. In addition, unwarranted use of broad-spectrum antimicrobials may favor the emergence of infectious strains [17].

The present study was planned keeping in view the grave dangers posed by the MDR bacteria in the ICUs. It is critical to assess the resistance patterns of the MDR bacteria and determine the factors involved in the acquisition and dissemination of these bacteria. This will be essential for planning proper treatment protocols for managing infections in ICUs.

The majority of infections occurred in the first quarter of the year $(47.4 \%)$, which could be explained by the fact that infection rates are higher in the winter months because of many factors, such as crowding of people at home, inadequate ventilation, low vitamin D levels, dry air, and decreased physical activity [18]. We observed that the majority $(76.7 \%)$ of the isolates were Gram-negative, and only $27.3 \%$ were Gram-positive isolations. A total of $55.0 \%$ of the infections were noted in males, and $35.0 \%$ of the infections occurred in patients above 75 years of age (Table 1). Gram-negative infections were more frequently observed in males (50.6\%) and in patients aged more than 75 years (32.3\%) (Table 2). Ibrahim observed in 2018 that $81 \%$ of the isolates were Gram-negative, and male patients (59.7\%) were predominant in that study [9]. The predominance of Gram-negative isolates in older male patients admitted to ICUs has been observed in studies conducted by Bianco et al., Sligl et al., and Lachhab et al. [19-21]. Males are generally more prone to infections than females, due to differences in the sex steroids as well as imbalance of sex-chromosomelinked genes [22]. The increased incidence in older age groups may be due to their defective defense mechanisms and deteriorating immune systems [21,23].

The most common bacteria detected in the ICUs in our study were K. pneumoniae (21.0), P. aeruginosa $(11.8 \%)$, and Staphylococcus aureus (13.2\%) (Table 1$)$. Iwuafor et al. found K. pneumoniae (13.6\%) to be the most common Gram-negative organism; bloodstream infections (49\%), followed by urinary tract infections $(35.6 \%)$, were the most common infections in their study [24] K. pneumoniae was the predominant organism noted in the studies carried out by Oliviera et al., Pokhrel et al., and Wang et al. [25-27]. K. pneumoniae is a facultative anaerobe, and is a common pathogen in hospital settings. Because of unrestricted use of broad-spectrum antimicrobials, and selective pressure applied therein, there is an increased generation of MDR and carbapenem-resistant strains of K. pneumoniae [28]. The predominance of bloodstream infections has been noted in studies carried out by 
Ak O et al., Moremi et al., and Frattari et al. [29-31]. In our study, Gram-negative isolates were recovered mainly from urine specimens (30.0\%), followed by blood specimens (25.6\%) (Table 2). Maximum isolations from urinary samples were observed by Ozer et al. and Mythri et al. [7,23].

The highest antimicrobial resistance was observed against ampicillin $(95 \%)$ and cephalothin (93.1\%) (Figure 2). Kumari et al. observed the highest resistance against ampicillin (97.6\%) and first-generation cephalosporins (98.8\%) [32]. An overall 73.2\% and $70.1 \%$ resistance was observed for third- and fourth-generation cephalosporins in our study (Figure 2). Ibrahim and Tan et al. also observed higher resistance rates, ranging from 63.3 to $70 \%$ and 75 to $88 \%$, respectively, against third- and fourth-generation cephalosporins [9,33]. A $>65 \%$ resistance rate was observed for fluoroquinolones in our study (Figure 2). A 61.5\% resistance rate for ciprofloxacin was observed by Ibrahim [9]. Tan et al. noted resistance of $>72 \%$ for fluoroquinolones [33].

We observed an overall carbapenem resistance rate of $48.2 \%$, with the lowest for meropenem (43\%) (Figure 2). Moolchandani et al. observed resistance of 33.9\% in their study [34], while Ibrahim noted a resistance rate of $>53 \%$ against carbapenems [9].

Amikacin was the most effective antibiotic, with a sensitivity rate of $69.5 \%$ in our study (Figure 2). Kumari et al. also observed the lowest mean resistance for amikacin (48.5\%), making it the most effective drug in their study [32]. Amikacin has also been found to be an effective drug in other studies; resistance rates of $48.1 \%, 40.5 \%$, and $43 \%$ were observed by Ibrahim, Moolchandani et al., and Leelarasamee et al., respectively [9,34,35].

Multidrug resistance (MDR) was observed in 372 (85.1\%) isolates of the Gram-negative bacteria (Table 3). An increased frequency of MDR isolates represents a worrying trend in treating the patients in the ICUs, warranting strict infection control measures in the hospitals and judicious use of antimicrobials. Similarly high degrees of MDR isolates $(87.07 \%$ and $89.5 \%)$ were also seen in the studies conducted by Siwakoti et al. [36] and Agyepong et al. [37], respectively. Ibrahim [9] noted MDR in 67.9\% of isolates, whereas Moolchandani et al. [34] observed MDR in 55.7\% of isolates.

All isolates of $A$. baumannii were MDR, whereas MDR isolates were seen in $60(95.2 \%)$ of P. aeruginosa, 57 (86.4\%) of P. mirabilis, 100 (83.3\%) of K. pneumoniae, and 50 (79.4\%) of E. coli (Table 3). Bianco et al. noted MDR phenotypes in all P. aeruginosa, and in $91.6 \%$ of A. baumannii, $40 \%$ of E. coli, and $52.3 \%$ of K. pneumoniae isolates [19], Ibrahim observed MDR in $97.5 \%$ of $A$. baumannii, $60.9 \%$ of $P$. aeruginosa, $46.7 \%$ of $P$. mirabilis, $59.3 \%$ of $K$. pneumoniae, and $43.2 \%$ of E. coli isolates [9]. Higher degrees of resistance observed in $A$. baumannii and $P$. aeruginosa have been attributed to the intrinsic resistance of these organisms to antimicrobials, as well as their potential to acquire resistant genes. Multiple resistance mechanisms include production of $\beta$-lactamases, metallo-carbapenemases, and aminoglycoside-modifying enzymes, as well as structural modifications in the membrane, mutations in topoisomerases, and increased activity of efflux pumps [38].

Overall, we observed 125 (28.6\%) extensively drug-resistant isolates of the Gramnegative bacteria (Table 3). XDR was noted in $79.5 \%$ of $A$. baumannii, $38.8 \%$ of P. aeruginosa, $9.09 \%$ of P. mirabilis, $21.7 \%$ of K. pneumoniae, and $20.6 \%$ of E. coli isolates. Hasanin et al. noted XDR in $65 \%$ of Gram-negative isolates, with $A$. baumannii $(86 \%)$, P. aeruginosa (63\%), P. mirabilis (61\%), K. pneumoniae (52\%), and E. coli (47\%) [39]. Parajuli et al. noted XDR in $43.3 \%$ of Gram-negative isolates, with Acinetobacter spp. (84.4\%), Pseudomonas spp. (62.5\%), Klebsiella spp. (48.6\%), and E. coli (19.3\%) [16]. The higher rates observed by Hasanin et al. and Parajuli et al. may be due to the local factors prevalent in their settings, such as unlimited antimicrobial use, increased induction, and dissemination of resistant strains. Many other studies, such as those conducted by Souza et al. and Qin et al., have reported lower XDR isolates in their studies $[40,41]$.

Multidrug-resistant strains $(88.9 \%)$ were recovered more frequently from female patients admitted to intensive care units. MDR isolates were also recovered at a higher frequency $(>75 \%)$ from all age groups (Table 4$)$. However, the predominance of MDR isolation in male patients has been observed by most other authors, including Ibrahim [9], 
Phu et al. [42], and Wang et al. [43]. The higher rates MDR isolates in female patients seen in our study may be attributed to the fact that rates of female hospital admission were almost equal to the rates of male admission, whereas in the studies cited above the rates of male hospital admission far exceeded the female admission rates.

This is the first study on antimicrobial resistance observed in various clinical specimens of patients admitted to this region's intensive care units. This study highlights the importance of identifying the reasons for this high antimicrobial resistance, and developing strategies to tackle this issue. The use of recent data on antimicrobial resistance is the major strength of this study. The non-availability of molecular data on this resistance is the main limitation of this study.

\section{Conclusions}

We conclude that Gram-negative bacteria cause the majority of infections in intensive care patients. A high frequency of MDR Gram-negative bacteria was observed, with moderate amounts of XDR bacteria. Factors favoring MDR include female gender and advancing age.

The increased frequency of MDR Gram-negative bacteria represents a worrying trend, and warrants enhanced surveillance programs, strict infection control measures, and strengthening of the antimicrobial stewardship program.

Author Contributions: Conceptualization, F.A.W. and A.B.; methodology, A.B., A.T. and B.T.; software, F.A.W., A.B. and A.T.; validation, M.J.S.A., A.I.A., A.S.A., B.T., M.U.S. and M.D.; formal analysis, A.B., A.T., M.J.S.A., A.I.A. and A.S.A.; investigation, F.A.W., M.U.S. and B.T.; resources, A.B., M.J.S.A., A.I.A., A.S.A. and M.D.; data curation, A.B., A.T. and B.T.; writing-original draft preparation, F.A.W. and A.B.; writing-review and editing, F.A.W., M.J.S.A., A.I.A., A.S.A., B.T., M.U.S. and M.D.; visualization, M.J.S.A., A.I.A., A.S.A., M.U.S. and M.D.; supervision, F.A.W., A.B. and A.T.; project administration, F.A.W. and A.B. All authors have read and agreed to the published version of the manuscript.

Funding: This research received no external funding.

Institutional Review Board Statement: The study was conducted according to the guidelines of the Declaration of Helsinki, and approved by the Ethics Committee of JOUF UNIVERSITY (research protocol no. 03/04/41 dated 6 January 2020).

Informed Consent Statement: Our study involved the analysis of antibiograms from the microbiology unit of the study hospital. There was no direct contact with the patients; hence, no consent was required. However, as a standard operating procedure practiced in this hospital, patients' and/or relatives' informed consent is taken before carrying out any procedure on patients admitted to ICUs, and the same is recorded in the files.

Data Availability Statement: Data will be made available on request.

Acknowledgments: We thank the Ministry of Health, Saudi Arabia for facilitating our access to the patients' data.

Conflicts of Interest: The authors declare no conflict of interest.

\section{References}

1. Who.int. Antimicrobial Resistance. Available online: https://www.who.int/news-room/fact-sheets/detail/antimicrobialresistance (accessed on 11 July 2020).

2. Holmes, A.H.; Moore, L.S.; Sundsfjord, A.; Steinbakk, M.; Regmi, S.; Karkey, A.; Guerin, P.J.; Piddock, L.J. Understanding the mechanisms and drivers of antimicrobial resistance. Lancet 2016, 387, 176-187. [CrossRef]

3. Who.int. WHO Publishes List of Bacteria for which New Antibiotics Are Urgently Needed. Available online: https:// www.who.int/news-room/detail/27-02-2017-who-publishes-list-of-bacteria-for-which-new-antibiotics-are-urgently-needed (accessed on 11 July 2020).

4. Peleg, A.Y.; Hooper, D.C. Hospital-acquired infections due to gram-negative bacteria. N. Engl. J. Med. 2010, 362, 1804-1813. [CrossRef] [PubMed]

5. World Health Organization. The Burden of Health Care-Associated Infection Worldwide. Available online: https:/ /www.who. int/infection-prevention/publications/burden_hcai/en/. (accessed on 12 July 2020). 
6. Vincent, J.-L.; Rello, J.; Marshall, J.; Silva, E.; Anzueto, A.; Martin, C.D.; Moreno, R.; Lipman, J.; Gomersall, C.; Sakr, Y.; et al. International Study of the Prevalence and Outcomes of Infection in Intensive Care Units. JAMA 2009, 302, 2323-2329. [CrossRef] [PubMed]

7. Ozer, B.; Ozbakıs Akkurt, B.C.; Duran, N.; Onlen, Y.; Savas, L.; Turhanoglu, S. Evaluation of nosocomial infections and risk factors in critically ill patients. Med. Sci. Monit. 2011, 17, 17-22. [CrossRef]

8. Ylipalosaari, P.; Ala-Kokko, T.I.; Laurila, J.; Ohtonen, P.; Syrjälä, H. Intensive care acquired infection is an independent risk factor for hospital mortality: A prospective cohort study. Crit. Care 2006, 10, R66. [CrossRef]

9. Ibrahim, M.E. High antimicrobial resistant rates among Gram-negative pathogens in intensive care units. A retrospective study at a tertiary care hospital in Southwest Saudi Arabia. Saudi Med. J. 2018, 39, 1035-1043. [CrossRef]

10. Shorman, M.; Al-Tawfiq, J.A. Risk factors associated with vancomycin-resistant enterococcus in intensive care unit settings in saudi arabia. Interdiscip. Perspect. Infect. Dis. 2013, 2013, 369674. [CrossRef]

11. Somily, A.M.; Alsubaie, S.S.; BinSaeed, A.A.; Torchyan, A.A.; Alzamil, F.A.; Al-Aska, A.I.; Al-Khattaf, F.S.; Khalifa, L.A.; AlThawadi, S.I.; Alaidan, A.A.; et al. Extended-spectrum $\beta$-lactamase-producing Klebsiella pneumoniae in the neonatal intensive care unit: Does vancomycin play a role? Am. J. Infect. Control 2014, 42, 277-282. [CrossRef]

12. Amer, M.R.; Akhras, N.S.; Mahmood, W.A.; Al-Jazairi, A.S. Antimicrobial stewardship program implementation in a medical intensive care unit at a tertiary care hospital in Saudi Arabia. Ann. Saudi Med. 2013, 33, 547-554. [CrossRef] [PubMed]

13. CLSI. Performance Standards for Antimicrobial Susceptibility Testing, 27th ed.; CLSI Supplement M100; Clinical and Laboratory Standards Institute: Wayne, PA, USA, 2017.

14. Magiorakos, A.-P.; Srinivasan, A.; Carey, R.; Carmeli, Y.; Falagas, M.; Giske, C.; Harbarth, S.; Hindler, J.; Kahlmeter, G.; OlssonLiljequist, B. Multidrug-resistant, extensively drug-resistant and pandrug-resistant bacteria: An international expert proposal for interim standard definitions for acquired resistance. Clin. Microbiol. Infect. 2012, 18, 268-281. [CrossRef] [PubMed]

15. Maseda, E.; Mensa, J.; Valía, J.C.; Gomez-Herreras, J.I.; Ramasco, F.; Samso, E.; Chiveli, M.A.; Pereira, J.; González, R.; Aguilar, G.; et al. Bugs, hosts and ICU environment: Countering pan-resistance in nosocomial microbiota and treating bacterial infections in the critical care setting. Rev. Esp. Anestesiol. Reanim. 2014, 61, e1-e19. [CrossRef] [PubMed]

16. Parajuli, N.P.; Acharya, S.P.; Mishra, S.K.; Parajuli, K.; Rijal, B.P.; Pokhrel, B.M. High burden of antimicrobial resistance among gram negative bacteria causing healthcare associated infections in a critical care unit of Nepal. Antimicrob. Resist. Infect. Control 2017, 6, 67. [CrossRef] [PubMed]

17. Strich, J.R.; Palmore, T.N. Preventing Transmission of Multidrug-Resistant Pathogens in the Intensive Care Unit. Infect. Dis. Clin. N. Am. 2017, 31, 535-550. [CrossRef]

18. Fares, A. Factors influencing the seasonal patterns of infectious diseases. Int. J. Prev. Med. 2013, 4, 128. [PubMed]

19. Bianco, A.; Capano, M.S.; Mascaro, V.; Pileggi, C.; Pavia, M. Prospective surveillance of healthcare-associated infections and patterns of antimicrobial resistance of pathogens in an Italian intensive care unit. Antimicrob. Resist. Infect. Control 2018, 7, 48. [CrossRef] [PubMed]

20. Sligl, W.I.; Dragan, T.; Smith, S.W. Nosocomial Gram-negative bacteremia in intensive care: Epidemiology, antimicrobial susceptibilities, and outcomes. Int. J. Infect. Dis. 2015, 37, 129-134. [CrossRef]

21. Lachhab, Z.; Frikh, M.; Maleb, A.; Kasouati, J.; Doghmi, N.; Ben Lahlou, Y.; Belefquih, B.; Lemnouer, A.; Elouennass, M. Bacteraemia in Intensive Care Unit: Clinical, Bacteriological, and Prognostic Prospective Study. Can. J. Infect. Dis. Med. Microbiol. 2017, 2017, 4082938. [CrossRef]

22. Vom Steeg, L.G.; Klein, S.L. SeXX Matters in Infectious Disease Pathogenesis. PLoS Pathog. 2016, 12, e1005374. [CrossRef] [PubMed]

23. Mythri, H.; Kashinath, K. Nosocomial infections in patients admitted in intensive care unit of a tertiary health center, India. Ann Med. Health Sci. Res. 2014, 4, 738-741. [CrossRef]

24. Iwuafor, A.A.; Ogunsola, F.T.; Oladele, R.O.; Oduyebo, O.O.; Desalu, I.; Egwuatu, C.C.; Nnachi, A.U.; Akujobi, C.N.; Ita, I.O.; Ogban, G.I. Incidence, Clinical Outcome and Risk Factors of Intensive Care Unit Infections in the Lagos University Teaching Hospital (LUTH), Lagos, Nigeria. PLoS ONE 2016, 11, e0165242. [CrossRef]

25. Oliveira, P.M.N.; Buonora, S.N.; Souza, C.L.P.; Simões Júnior, R.; Silva, T.C.D.; Bom, G.J.T.; Teixeira, C.; Silva, A. Surveillance of multidrug-resistant bacteria in pediatric and neonatal intensive care units in Rio de Janeiro State, Brazil. Rev. Soc. Bras. Med. Trop. 2019, 52, e20190205. [CrossRef] [PubMed]

26. Pokhrel, B.; Koirala, T.; Shah, G.; Joshi, S.; Baral, P. Bacteriological profile and antibiotic susceptibility of neonatal sepsis in neonatal intensive care unit of a tertiary hospital in Nepal. BMC Pediatr. 2018, 18, 208. [CrossRef]

27. Wang, C.; Yuan, Z.; Huang, W.; Yan, L.; Tang, J.; Liu, C.W. Epidemiologic analysis and control strategy of Klebsiella pneumoniae infection in intensive care units in a teaching hospital of People's Republic of China. Infect. Drug Resist. 2019, 12, 391-398. [CrossRef] [PubMed]

28. Galán, J.C.; González-Candelas, F.; Rolain, J.M.; Cantón, R. Antibiotics as selectors and accelerators of diversity in the mechanisms of resistance: From the resistome to genetic plasticity in the $\beta$-lactamases world. Front. Microbiol. 2013, 4, 9. [CrossRef] [PubMed]

29. Ak, O.; Batirel, A.; Ozer, S.; Çolakoğlu, S. Nosocomial infections and risk factors in the intensive care unit of a teaching and research hospital: A prospective cohort study. Med. Sci. Monit. 2011, 17, 29-34. [CrossRef] [PubMed]

30. Moremi, N.; Claus, H.; Mshana, S.E. Antimicrobial resistance pattern: A report of microbiological cultures at a tertiary hospital in Tanzania. BMC Infect. Dis. 2016, 16, 756. [CrossRef] 
31. Frattari, A.; Savini, V.; Polilli, E.; Di Marco, G.; Lucisano, G.; Corridoni, S.; Spina, T.; Costantini, A.; Nicolucci, A.; Fazii, P.; et al. Control of Gram-negative multi-drug resistant microorganisms in an Italian ICU: Rapid decline as a result of a multifaceted intervention, including conservative use of antibiotics. Int. J. Infect. Dis. 2019, 84, 153-162. [CrossRef]

32. Kumari, H.B.; Nagarathna, S.; Chandramuki, A. Antimicrobial resistance pattern among aerobic gram-negative bacilli of lower respiratory tract specimens of intensive care unit patients in a neurocentre. Indian J. Chest Dis. Allied Sci. 2007, 49, 19-22.

33. Tran, G.M.; Ho-Le, T.P.; Ha, D.T.; Tran-Nguyen, C.H.; Nguyen, T.S.M.; Pham, T.T.N.; Nguyen, T.A.; Nguyen, D.A.; Hoang, H.Q.; Tran, N.V.; et al. Patterns of antimicrobial resistance in intensive care unit patients: A study in Vietnam. BMC Infect. Dis. 2017, 17, 429. [CrossRef]

34. Moolchandani, K.; Sastry, A.S.; Deepashree, R.; Sistla, S.; Harish, B.N.; Mandal, J. Antimicrobial Resistance Surveillance among Intensive Care Units of a Tertiary Care Hospital in Southern India. J. Clin. Diagn. Res. 2017, 11, DC01-DC07. [CrossRef]

35. Leelarasamee, A.; Janyapoon, K. Antimicrobial resistance of 100 serial gram-negative isolates in two intensive care units. J. Med. Assoc. Thai. 1992, 75, 680-687.

36. Siwakoti, S.; Subedi, A.; Sharma, A.; Baral, R.; Bhattarai, N.R.; Khanal, B. Incidence and outcomes of multidrug-resistant gram-negative bacteria infections in intensive care unit from Nepal-A prospective cohort study. Antimicrob. Resist. Infect. Control 2018, 7, 114. [CrossRef]

37. Agyepong, N.; Govinden, U.; Owusu-Ofori, A.; Essack, S.Y. Multidrug-resistant gram-negative bacterial infections in a teaching hospital in Ghana. Antimicrob. Resist. Infect. Control 2018, 7, 37. [CrossRef] [PubMed]

38. Bonomo, R.A.; Szabo, D. Mechanisms of Multidrug Resistance in Acinetobacter Species and Pseudomonas aeruginosa. Clin. Infect. Dis. 2006, 43, S49-S56. [CrossRef] [PubMed]

39. Hasanin, A.; Eladawy, A.; Mohamed, H.; Salah, Y.; Lotfy, A.; Mostafa, H.; Ghaith, D.; Mukhtar, A. Prevalence of extensively drug-resistant gram negative bacilli in surgical intensive care in Egypt. Pan Afr. Med. J. 2014, 19, 177. [CrossRef]

40. Souza, G.L.; Rocha, R.F.d.A.; Silveira, A.D.N.; Dias Duarte de Carvalho, H.; Oliveira, C.D.M.; Leite, E.M.M.; Silva, E.U.; Giarola, L.G.; Couto, B.R.G.M.; Starling, C.E.F. 2475. Incidence of Multidrug-Resistant, Extensively Drug-Resistant and Pandrug-Resistant Gram-Negative Bacteria in Brazilian Intensive Care Units. Open Forum Infect. Dis. 2019, 6, S857. [CrossRef]

41. Qin, Y.; Chen, X.; Huang, D.; Wei, L. Distribution and drug resistance profiles of pathogenic bacteria isolated from patients with nosocomial infection in intensive care unit. Nan Fang Yi Ke Da Xue Xue Bao 2012, 32, 1513-1515.

42. Phu, V.D.; Wertheim, H.F.; Larsson, M.; Nadjm, B.; Dinh, Q.D.; Nilsson, L.E.; Rydell, U.; Le, T.T.; Trinh, S.H.; Pham, H.M.; et al. Burden of Hospital Acquired Infections and Antimicrobial Use in Vietnamese Adult Intensive Care Units. PLoS ONE 2016, 11, e0147544. [CrossRef]

43. Wang, M.; Wei, H.; Zhao, Y.; Shang, L.; Di, L.; Lyu, C.; Liu, J. Analysis of multidrug-resistant bacteria in 3223 patients with hospital-acquired infections (HAI) from a tertiary general hospital in China. Bosn. J. Basic Med. Sci. 2019, 19, 86. [CrossRef] 